\title{
Primary Health Care Physicians' Knowledge on Brucellosis, Its Prevention, Diagnosis, and Management - A Cross Section Survey in Prince Sultan Military Medical City, Riyadh, Saudi Arabia
}

\author{
Mahdi Mohammed Alrajhi ${ }^{1}$ \\ ${ }^{1}$ Department of Family Medicine, Prince Sultan Military Medical City, Riyadh, Saudi Arabia.
}

\section{ABSTRACT}

\section{BACKGROUND}

Human brucellosis is a prevalent zoonotic disease. It can be transmitted by exposure to an infected animal, and by consumption of contaminated milk and dairy products. Saudi Arabia is considered as an endemic area for human brucellosis. We wanted to assess the knowledge and practice of primary health care physicians with regard to diagnosis, treatment, and prevention of brucellosis.

\section{METHODS}

This study included 124 primary care physicians in Prince Sultan Military City in Riyadh from March 2016 to August 2017. A survey was used to assess knowledge and practice on human brucellosis that included three sections - Section A to investigate demographics, Section B to assess knowledge, and Section $C$ to assess practice. Validity of the questionnaire was proved, and the reliability was found to be $84.1 \%$ and response rate $86.7 \%$.

\section{RESULTS}

Good knowledge of human brucellosis was found in general, and consultants have the higher level of knowledge in comparison to freshly graduated physicians, and general practitioners. Long experience has a positive relationship with knowledge and practice with regard to human brucellosis.

\section{CONCLUSIONS}

Lack of knowledge and practice of primary care physicians, general practitioners, and freshly graduated physicians, on human brucellosis could be among the contributing factors to under-diagnosis and under-reporting of brucellosis cases in primary health care centres in Riyadh, Saudi Arabia. There is a demand for refresher programs, and lectures among physicians. Their teaching curricula should lay more emphasis on brucellosis.

\section{KEY WORDS}

Brucellosis, Malta Fever, Primary Care, Family Medicine, Saudi Arabia
Corresponding Author: Dr. Mahdi Mohammed Alrajhi. Department of Family Medicine, Prince Sultan Military Medical City, Riyadh, Saudi Arabia.

E-mail: alrajhi9@gmail.com

DOI: $10.14260 / \mathrm{jemds} / 2020 / 781$

How to Cite This Article:

Alrajhi MM. Primary health care physicians knowledge on brucellosis its prevention, diagnosis and management - a cross section survey in prince sultan military medical city, Riyadh, Saudi Arabia. J Evolution Med Dent Sci 2020;9(47):3560-3565, DOI: $10.14260 /$ jemds $/ 2020 / 781$

Submission 01-05-2020,

Peer Review 10-10-2020,

Acceptance 16-10-2020,

Published 23-11-2020.

Copyright (C) 2020 JEMDS. This is an open access article distributed under Creative Commons Attribution License [Attribution 4.0 International (CC BY 4.0)] 


\section{BACKGROUND}

Brucellosis is caused by a gram-negative facultative intracellular coccobacilli of Brucella genus. ${ }^{1,2}$ Though Brucella abortus infects cattle in preponderance, there are instances of Brucella melitensis too.3,4 Humans too are not exceptions in terms of infections caused by them. The tainted cattle may infest humans too either by direct exposure or by indirect contact. Even the defiled surroundings may cause infection to humans. Diffusion through food material too is responsible for infections in humans. ${ }^{5-7}$ There is no reported evidence of one to one conduction as such. However, contaminated biological items and conditions like impure blood exercised for transfusion, contaminated tissue, infected bone marrow deployed in transplant as well as any sexual contact with tainted individual may spread contamination. ${ }^{5}$ The quantifiable appearance of brucellosis in human beings emerges as an imprecise flu-like pattern like deteriorating fever, headache, common bodily disquiet etc. On the other hand, brucellosis in cattle creates generative damages.5,8-11

If the disease is eliminated in animals, it can be eradicated from humans too. ${ }^{12}$ For the very first time, the source of the ailment of a person (David Bruce) was cut off from the spleen of a soldier who in due course passed away from the illness. ${ }^{13}$

In many nations worldwide the root cause for such infections include consumption of products related to the unpasteurized milk or by contact to contaminated placental stuff, abandoned foetuses of tainted cattle. ${ }^{14}$ There is one more interesting fact that the exercise of burning dried dung as fuel for food preparation or other household chores too may prop up in infectivity in houses. ${ }^{15}$ Brucellosis is an illness which highly affect persons in some specific occupation. They can exceedingly infect veterinarians, farmers and inseminators. Poor living conditions are the other side of spread and contamination of this disease. Sadly, since marginalized section of the society live closer to their animals because of space restrictions or meagre livelihood, they are very prone to such infections. Unawareness and deprivation to the medical exposure are extended responsible factors of illness and its stretch in poor society. Moreover, the zoonosis nature of brucellosis is added disadvantage to the individuals, which affects both in equal measure i.e., humans and animals. Southwest part of Uganda has been reported to have an increasing number of Brucella illness in animals. The reason behind such disappointing figure takes its origin from the fact that there is very limited and irregular practice of animal screening. Abortions and field test results have been reported by the traders to be a leading cause of infection in animals. Earlier researches have stated that unscreened cattle particularly infected animals moved to other regions of the country from western region and potentially exposed animals to Brucella infection of those regions. ${ }^{16}$

Keeping in view the previously established facts in case of the disease caused by Brucella and the findings from the stakeholders of animal health service on the mounting occurrence of brucellosis in western region of Uganda, this work utilized a probable diagnosis as suggested by OIE (World Organisation for Animal Health) and WHO (World Health Organisation) by using RBT (Rose Bengal Test) for screening to settle on the possible animal and, human and cattle seroprevalence and in addition recognize related hazardous aspects for Brucella contamination among the individuals keeping cattle as well as their cattle in a high livestock dense part in the western part of Uganda. The objective of the study is to supply data desired to rationalize the requirement for unremitting brucellosis observation, management and preclusion in exceedingly widespread region.

So the objectives of the study were to assess the primary care physicians' level of knowledge regarding brucellosis preventions and modes of transmission, common presentation, diagnosis, and treatment and to determine the primary care physicians' practice level regarding brucellosis prevention, diagnosis, and treatment.

The study aimed to increase the awareness of primary care physicians toward brucellosis prevalence, diagnosis, management and prevention which in turn will improve the care level of physicians toward patients.

\section{METHODS}

This study is a cross-sectional survey that was conducted between March 2016 and August 2017.

\section{Study Area}

All Prince Sultan Military Medical City Primary Care Centres in Riyadh. These primary health care centres are serving more than 1500 patients daily of different ages of both genders distributed over about 60 clinics including Well- Baby Care, general adult, antenatal care, women health, prevention of chronic diseases and emergency clinics.

\section{Sample Size}

The sample size was calculated by "Survey System Calculator" as (124), with confidence level $95 \%$, confidence interval 5 and total number of physicians 182.

\section{Sampling Technique}

Simple random sampling technique was used to choose 124 physicians out of the total 182. Physicians were chosen by random number generation method using MS excel.

\section{Study Instrument (Questionnaire) and Data Collection}

A multiple-choice questionnaire developed by the researcher. Which consists of three sections in addition to ethical consent: Section A includes demographic data. Section B includes questions to assess knowledge of physicians toward brucellosis types, modes of transmission, common clinical presentations, diagnosis, and management. Section C includes questions to assess the practice of physicians toward human brucellosis diagnosis, management, and prevention.

The questionnaire reviewed by the research supervisor and biostatistician for any unclear question or choices and assessment of scoring system of the questionnaire. After that, the questionnaire was piloted (pilot study) by distributing it over 15 family medicine physicians and experts in Alwazarat Primary Health Care Centre. Then, collected at the end of the office and clinic time; fifteen questionnaires distributed, fifteen questionnaires completed. It was pleasing and 
welcomed for all the comments and recommendations written on the questionnaire by the physicians.

Also, the questionnaire revealed as valid for face-to-face validation. The validity was tested by face-to-face validation with five primary care consultants and experts. And the answers were same as their answers in questionnaires.

The reliability of questionnaire tested by a distribution of 10 questionnaires on primary care physicians in King Khaled University Hospital in Riyadh over the period from 7 - 28 May. The reliability percentage is $84.1 \%$. An introduction regarding study and questionnaire was presented verbally at the time of data collection. And written, a clear introduction was on the first lines of the questionnaire with the consent form to decrease non-response rate as possible.

Questionnaires distributed at clinics of Primary Health Care Centers. Either early in first minutes or at the end of session time. Consent was taken from the administration for questionnaires distribution and to allow for few minutes for participants to fill the questionnaire (maximum 5 minutes for each questionnaire). Once the participant finished his questionnaire but not completed, the researcher asked him kindly to fulfil the gaps and complete it at the same time. If he refused, the questionnaire and participant cancelled and excluded from the study.

\section{Ethical Consideration}

This survey was carried out after approval by the hospital Research and Ethics Committee. Taking into account the complete confidentiality of all participants and not distinguishing between them in any way during the sampling process.

\section{Data Analysis}

Descriptive analysis was carried out. Qualitative data was presented with percentages and frequencies and quantitative data was presented with mean and standard deviation. ANOVA test was applied to compare statistical significance of average knowledge and practice scores between different sociodemographic characteristics when there are more than two groups. Independent sample t-test was used to compare when there are only two groups. Data were analysed using SPSS (version 22). A p-value of less than 0.05 was considered statistically significant.

\section{RESULTS}

The present study was performed among 124 individuals and the response rate was $86.71 \% .72(58.1 \%)$ of them were males and $52(41.9 \%)$ were females, the age range of participants was 25 - 69 with a mean of $34 \pm 9$ and the years of experience ranged from 0 to 40 years with a mean of $8 \pm 8$. Most of participants were Saudi 87 (70.2 \%) and 37 (29.8\%) were Non-Saudi. Residents represented the large majority of participants 56 (45.2\%), followed by consultants $21(16.9 \%)$ and an equal percent of $15.3 \%$ (19 individuals) for senior registrar and general practitioner and 9 (7.3 \%) were registrar. Participants had several different qualifications and other characteristics of participants are shown in table 1 below.

\begin{tabular}{|cc|}
\hline Characteristics & N (\%) \\
Gender & $72(58.1 \%)$ \\
Male & $52(41.9 \%)$ \\
Female & \\
Nationality & $87(70.2 \%)$ \\
Saudi & $37(29.8 \%)$ \\
Non Saudi & \\
Job Position & $9(7.3 \%)$ \\
Registrar & $19(15.3 \%)$ \\
Senior Registrar & $56(45.2 \%)$ \\
Resident & $19(15.3 \%)$ \\
General Practitioner & $21(16.9 \%)$ \\
Consultant & $3(2.4 \%)$ \\
Qualification & $1(0.8 \%)$ \\
Arab Board & $1(0.8 \%)$ \\
FCPS & $1(0.8 \%)$ \\
FMACP & $1(0.8 \%)$ \\
FRCP / FCGP & $1(0.8 \%)$ \\
Jordan Board & $67(54 \%)$ \\
Master Family Medicine & $21(16.9 \%)$ \\
MBBS & $1(0.8 \%)$ \\
MRCGP & $1(0.8 \%)$ \\
MRCGP, Arab Board & $26(21 \%)$ \\
MRCP & \\
Saudi Board &
\end{tabular}

\begin{tabular}{|c|c|c|}
\hline Demographics & Knowledge & Practice \\
\hline \multicolumn{3}{|l|}{ Age groups } \\
\hline$<30$ & $3.6 \pm 0.43$ & $2.28 \pm 0.85$ \\
\hline $30-39$ & $3.87 \pm 0.52$ & $2.84 \pm 0.77$ \\
\hline $40-49$ & $4.1 \pm 0.47$ & $2.98 \pm 0.77$ \\
\hline$\geq 50$ & $4.08 \pm 0.47$ & $3.4 \pm 0.47$ \\
\hline P-value & $0.001^{*}$ & $0.001 *$ \\
\hline \multicolumn{3}{|l|}{ Gender } \\
\hline Male & $3.85 \pm 0.49$ & $2.73 \pm 0.88$ \\
\hline Female & $3.78 \pm 0.53$ & $2.66 \pm 0.8$ \\
\hline P-value & 0.4 & 0.6 \\
\hline \multicolumn{3}{|l|}{ Nationality } \\
\hline Saudi & $3.8 \pm 0.51$ & $2.66 \pm 0.88$ \\
\hline Non Saudi & $3.87 \pm 0.5$ & $2.81 \pm 0.76$ \\
\hline P-value & 0.4 & 0.3 \\
\hline \multicolumn{3}{|l|}{ Job Position } \\
\hline Registrar & $4.05 \pm 0.4$ & $2.75 \pm 0.78$ \\
\hline Senior registrar & $4.05 \pm 0.5$ & $2.89 \pm 0.8$ \\
\hline Resident & $3.6 \pm 0.39$ & $2.47 \pm 0.87$ \\
\hline General Practitioner & $3.61 \pm 0.43$ & $2.39 \pm 0.68$ \\
\hline Consultant & $4.27 \pm 0.5$ & $3.41 \pm 0.5$ \\
\hline P-value & $0.001 *$ & $0.001 *$ \\
\hline \multicolumn{3}{|l|}{ Qualification } \\
\hline Arab Board & $3.54 \pm 0.35$ & $2.91 \pm 0.52$ \\
\hline FCPS & $3.87 \pm 0$ & $2.5 \pm 0$ \\
\hline FMACP & $3.87 \pm 0$ & $2 \pm 0$ \\
\hline FRCP / FCGP & $4.62 \pm 0$ & $3.75 \pm 0$ \\
\hline Jordan Board & $4.25 \pm 0$ & $3 \pm 0$ \\
\hline Master Family Medicine & $4.06 \pm 0$ & $3.25 \pm 0$ \\
\hline MBBS & $3.62 \pm 0.38$ & $2.47 \pm 0.84$ \\
\hline MRCGP & $3.9 \pm 0.6$ & $2.92 \pm 0.85$ \\
\hline MRCGP, Arab Board & $4.18 \pm 0$ & $2.75 \pm 0$ \\
\hline MRCP & $3.93 \pm 0$ & $3 \pm 0$ \\
\hline Saudi Board & $4.21 \pm 0.52$ & $3.06 \pm 0.78$ \\
\hline P-value & $0.001^{*}$ & 0.1 \\
\hline \multicolumn{3}{|c|}{$\begin{array}{l}\text { Table 2. Correlation between Demographics and } \\
\text { Total Score of Both Knowledge and Practice }\end{array}$} \\
\hline
\end{tabular}

Scoring system was used to assess knowledge and practice of participants, the scoring of knowledge ranged from 1 to 5 points, the scoring of practice ranged from 1 to 4 points. The range of knowledge score was 2.63 - 5 with a mean of $3.82 \pm$ 0.51 and the score of practice ranged from $1-4$ with a mean of $2.7 \pm 0.84$. Regarding knowledge, score $>3$ referred to good knowledge while score $\leq 3$ referred to bad knowledge. Regarding practice, score $>2$ referred to good practice, while score $\leq 2$ referred to bad practice. There was a significant difference of knowledge mean scores and practice scores between different age groups $(\mathrm{p}<0.001)$. Physicians with older age had good knowledge scores and practice scores as compared to younger physicians. Physician with age $\geq 50$ had the average score of $4.08 \pm 0.47$ while it was $3.6 \pm 0.43$ with age $<30$ years of age and average practice scores in $\geq 50$ age 
group was $3.4 \pm 0.47$ while it was $2.28 \pm 0.85$ in $<30$ group. It was also observed that there were significant differences between physicians with different positions. Consultants had high average knowledge scores $4.27 \pm 0.5$ and practice scores $3.41 \pm 0.5$ as compared other physicians $(\mathrm{p}<0.001)$. Results showed that there were significant differences in knowledge scores among the physicians with different qualification $(\mathrm{p}<$ 0.001), however though practice scores were high among the doctors who were FRCP / FCGP qualified, but it was not statistically significant $(p=0.1)$. Physicians qualified with FRCP / FCGP had high knowledge and practice compared to physicians with other qualifications.
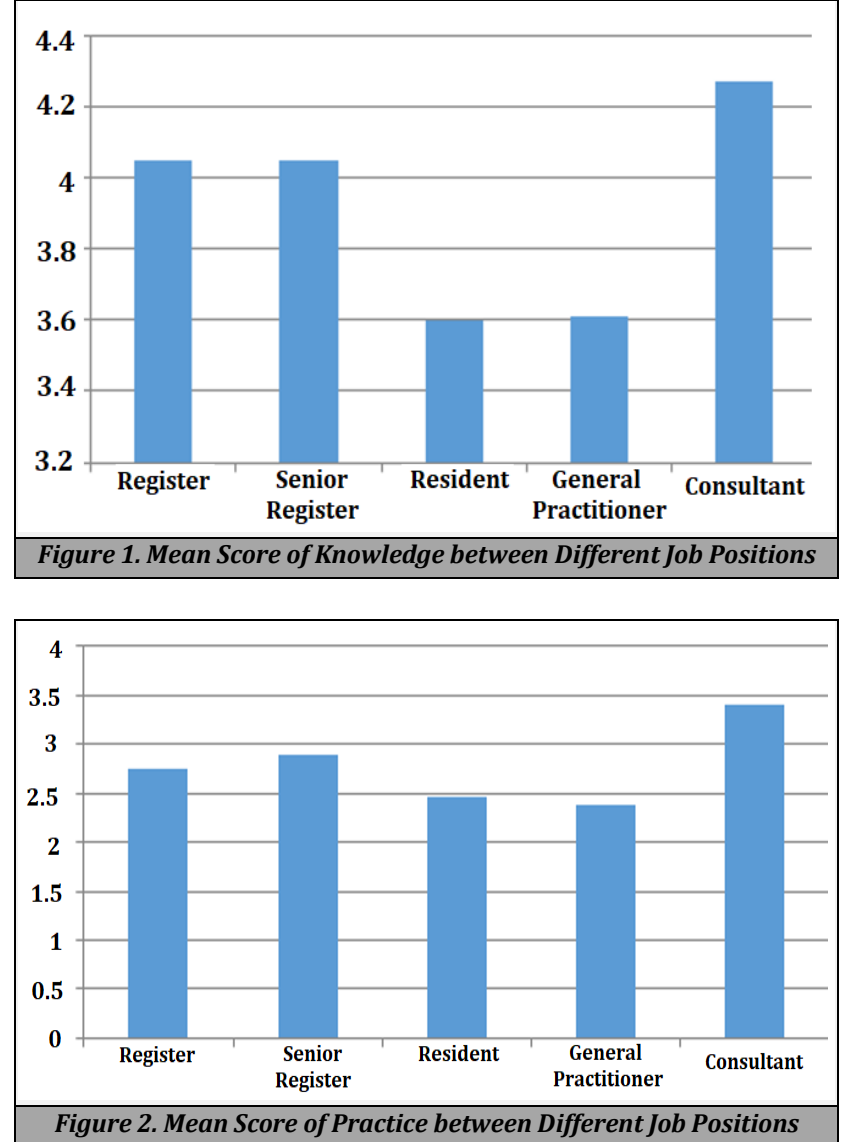

The questions from 1 to 12 assessed the knowledge of brucellosis diagnosis, the mean score was 3.9 , and $74 \%$ had good knowledge about brucellosis diagnosis, the questions from 13 - 16 investigated the knowledge of brucellosis treatment, the mean score was 4.2 with $88.7 \%$ had good knowledge.

Question 17 in practice section, studied prevention of brucellosis. And $55.6 \%$ had a good practice with a score of 2.95. Question 18 studied the practice of diagnosis, only $25 \%$ had good practice with a mean score of 2.1. Questions $19-20$, investigated treatment practice, $65 \%$ had good practice with a mean score of 2.6.

The last two questions in the questionnaire were to evaluate the number of cases of Brucella diagnosed by the physician and to investigate if he was trained. Most of participants 66 (53.2\%) diagnose brucellosis at least once per years, 38 (30.6 \%) never diagnosed it, 17 (13.7\%) diagnosed it at least once per month, and 3 (2.4\%) diagnosed it once per week. There was a significant variation between the number of times brucellosis was diagnosed by the participants and age of them ( $\mathrm{p}$-value < 0.001). Also, there was a significant difference between years of experience and number of brucellosis diagnosed. Regarding gender, there was no significant difference between gender and number of brucellosis diagnosed ( $p$-value $=0.38$ ), there were significances found regarding nationality ( $p$-value $=0.003$ ), job position ( $\mathrm{p}$-value $=0.001$ ) and qualifications of doctors ( $\mathrm{p}$ value $=0.004)$.

By asking participants about training, there were 52(41.9 \%) participants who received a training on human brucellosis diagnosis and management, while $50(40.3 \%)$ didn't receive any training and $22(17.7 \%)$ couldn't remember. There was no significant difference regarding receiving training and age ( $\mathrm{p}$-value $=0.54)$ or years of experience $(\mathrm{p}$-value $=0.6)$. There were significances regarding receiving training and all other demographics, there were a significance difference regarding gender $(\mathrm{p}$-value $=0.03)$, regarding nationality $(\mathrm{p}$-value $=$ $0.003)$, regarding job position $(p$-value $=0.001)$ and regarding qualifications of doctors ( $\mathrm{p}$-value $=0.01$ ).

\section{DISCUSSION}

Like some of the previous studies done in the past, this work too utilizes RBT as the most advantageous in this resource restricted work area. ${ }^{11,17,18,19}$ As per the guidelines of WHO, case categorization of an affirmative case where RBT is deployed, is measured as a possible case and as per the suggestions recommended by OIE, a positive case in cattle where RBT is utilized is considered as presumptive. RBT is measured as a fitting test for the control of brucellosis in herds at the national or local level as it hardly ever gives bogus negatives. ${ }^{20}$ This study involves presumptively seropositive samples of almost one third of the total cattle size involved in this work which ranges up to $34.7 \%$ of the total ratio. This is in fact in connection to reports of the field supplied from the stakeholders of animal service, who carried out Brucella screening in cattle in a very haphazard and nonregular manner in this western part of the country and had indefatigably accounted boost in seroprevalence. This seroprevalence is in the proximity of the extent of a study done in South Sudan where RBT was performed. ${ }^{21}$ The RBT was deployed qualitatively and ailment substantiation was not performed as titres were not taken, yet, presumptive flock seroprevalence of seventy on percent was measured elevated in addition to an incidence of grave community and veterinary health worry because cattle exclusively circuitously or unswervingly contaminate humans and grave financial sufferings happen at time when they develop conditions like brucellosis. ${ }^{15}$ There are plentiful of resources too which direct that in a prevalent region with towering seroprevalence in cattle, the RBT is adequate test devoid of any need for a assenting examination to confer a populace depiction of the ailment standing. ${ }^{21}$ Researches have revealed that cattle species vulnerable to Brucella contamination can be unable to hold their titers of antibody.

People vulnerable to illness need awareness and information of brucellosis. The occupationally exposed individuals and community food security require added concentration. It has been earlier established that deficiency in acquaintance about the illness possibly will direct to an 
impediment in finding therapeutic aid and, therefore, a holdup in the investigation as well as in cure of the disease. ${ }^{22,23}$ Wrong findings in any disease over and over again pave way to a stoppage in healing and possibly upshot in long-term difficulty from the illness. ${ }^{24}$ Also, the squat brucellosis consciousness and acquaintance echelon of populace occupied in the livestock commerce can mount to an overlook in ailment avoidance and erroneous performs in dealing, catering and conserving cattle based foodstuff and therefore give way to hazardous conditions. ${ }^{25}$

It is observed from univariate study that the spot of the cattle within the parishes of Kyangundu and Kitojo augmented the likelihood for having flock that was presumptively Brucella seropositive. It was also illustrious from authorized communiqué from the office of the district veterinary officer that residents and farmers in these parishes are dangerously occupied in livestock commerce with steady selling and filling up of holdings with untested animal. Thus, this practice very likely put into elevated probability of Brucella seroprevalence in the group. There are many farmers in the study region who pay for cattle with progenitive conditions containing history of still births, abortions, and recurring breeders who fall short to conceive and these animals are easily supplied to inexperienced farmers. There is unfettered movement of cattle in the farms as well as in the study area which is very likely to widen of infection in the land.

As stated earlier, unpasteurized milk products were found to be the most usual means of spread of brucellosis. Another significant reason of the spread of the ailment comprise poor living conditions, burning dried dung as fuel for food preparing or other household chores, place restrictions or inadequate livelihood, lack of knowledge and deprivation to the medical exposure are extended accountable causes of disease and its outspread in poor populace.

In Hasanjani's research in Babol, unsullied and unpasteurized dairy foodstuffs were the major reason of morbidity of the disease. ${ }^{26}$ Also, In Ghasemi's research in the province of Kurdistan, utilization of dairy foodstuffs as well as concurrent touch with contaminated cattle, $48 \%$, and using up of unpasteurized dairy foodstuffs, $36.7 \%$, were found to be the foremost usual course of spread of brucellosis. ${ }^{27}$

The noteworthy feature of this research is its utilization of the RBT as an inexpensive screening test to portray rising Brucella contagion in animals as well as in humans. Furthermore, the effectiveness of this study is the evaluation of significant hazard aspects connected with the infection caused by Brucella in livestock keeping populace.

\section{CONCLUSIONS}

Knowledge and practice of primary care physicians on human brucellosis could be among the contributing factors to underdiagnosis and under-reporting of brucellosis cases in primary health care centers in Riyadh, Saudi Arabia. There is a demand for refresher programs, lectures, and workshops amongst the physicians. Their teaching curricula should lay more emphasis on brucellosis. This will provide primary care physicians with adequate knowledge with regard to brucellosis prevention, diagnosis, and treatment in the community.
The study suggests that any intervention to be engaged should give priority to primary care physicians especially those who work in the peripheral cities and rural villages.

Data sharing statement provided by the authors is available with the full text of this article at jemds.com.

Financial or other competing interests: None.

Disclosure forms provided by the authors are available with the full text of this article at jemds.com.

The author thanks the program director of family medicine residency program in Prince Sultan Military Medical City in Riyadh (Dr. Saad Albattal) for allowing the conduct of this research project. Special thanks to the supervisor of this research (Dr. Ghada Alarfaj). The author also thanks, Prof. Mustafa Alkofi, Dr. Ayman Afifi, Dr. Abu Obaida, Dr. Tarik Alsaid, and Dr. Fayez Bolus for all their efforts to complete this research.

\section{REFERENCES}

[1] Alton GG, Forsyth JRL. Brucella. Chap- 28. In: Baron S, ed. Medical microbiology. Galveson (TX): University of Texas Medical Branch 1996.

[2] Verma SK, Jain S, Kumar S. Immunogenicity and protective potential of a bacterially expressed recombinant dihydrolipoamide succinyl transferase (rE2o) of Brucella abortus in BALB/c mice. World J Microbiol Biotechnol 2012;28(7):2487-95.

[3] Spickler AR. Brucellosis: Brucella melitensis. 2018. Link: http://bit. ly/2U7E MSr.

[4] Bricker JB, Halling SM. Differentiation of Brucella abortus bv. 1, 2 and 4, Brucella melitensis, Brucella ovis, and Brucella suis bv.1 by PCR. J Clin Microbiol 1994;32(11):2660-6.

[5] Corbel MJ. Brucellosis in humans and animals. World Health Organization 2006.

[6] Holt HR, Eltholth MM, Hegazy YM, et al. Brucella spp. infection in large ruminants in an endemic area of Egypt: cross-sectional study investigating seroprevalence, risk factors and livestock owner's knowledge, attitudes and practices (KAPs). BMC Public Health 2011;11:341.

[7] Nabukenya I, Kaddu-Mulindwa D, Nasinyama GW. Survey of Brucella infection and malaria among Abattoir workers in Kampala and Mbarara Districts, Uganda. BMC Public Health 2013;13:901.

[8] Makita K, Fèvre EM, Waiswa C, et al. Herd prevalence of bovine brucellosis and analysis of risk factors in cattle in urban and peri-urban areas of the Kampala economic zone, Uganda. BMC Vet Res 2011;7:60.

[9] Musa MT, Abd Alla Shigidi MT, Saeed OM. Brucellosis in humans associated with animals. Saudi Med J 1999;20:311-5.

[10] Veterinary Services Centers for Epidemiology and Animal Health National Surveillance unit, National Bovine Brucellosis Surveillance Plan. United states department of Agriculture October 2012.

[11] Megersa B, Biffa D, Abunna F, et al. Seroepidemiological study of livestock brucellosis in a pastoral region. Epidemiol Infect 2012;140(5):887-96.

[12] Seleem MN, Boyle SM, Sriranganathan N. Brucellosis: a reemerging zoonosis. Vet Microbiol 2010;140(3-4):3928. 
[13] Institute of Environmental Science and Research Surveillance. Brucellosis, epidemiology in New Zealand. New Zealand: Public Health Surveillance. [Online] Available from: www. surv.esr.cri.nz.

[14] Galukande M, Muwazi S, Mugisa DB. Aetiology of low back pain in Mulago Hospital, Uganda. Afr Health Sci 2005;5(2):164-7.

[15] Corbel M. Brucellosis in humans and animals. FAO, OIE, WHO.http://www.who.int/csr/resources/publications/ Brucellosis.pdf.

[16] Mugizi DR, Boqvist S, Nasinyama GW, et al. Prevalence of and factors associated with Brucella sero-positivity in cattle in urban and peri-urban Gulu and Soroti towns of Uganda. J Vet Med Sci 2015;77(5):557-64.

[17] Mantur BG, Amarnath SK, Patil GA, et al. Clinical utility of a quantitative Rose Bengal slide agglutination test in the diagnosis of human brucellosis in an endemic region. Clin Lab 2014;60(4):533-41.

[18] Diaz R, Casanova A, Ariza J, et al. The Rose Bengal Test in human brucellosis: a neglected test for the diagnosis of a neglected disease. PLoS Negl Trop Dis 2011;5(4):e950.

[19] El-Fekhfakh EAM, Hassanain NAH, El-Folly RF, et al. Assessment of Rose Bengal test in diagnosing Egyptian human brucellosis. J Egypt Soc Parasitol 2011;41(2):497512.

[20] World Organization for Animal Health (OIE). Manual of diagnostic tests and vaccines for terrestrial animals. Vol. 1 and 2. 2018.
[21] Madut NA, Muwonge A, Nasinyama GW, et al. The seroprevalence of brucellosis in cattle and their herders in Bahr el Ghazal region, South Sudan. PLoS Negl Trop Dis 2018;12(6):e0006456.

[22] Kunda J, Fitzpatrick J, Kazwala R, et al. Health-seeking behaviour of human brucellosis cases in rural Tanzania. BMC Public Health 2007;7:315.

[23] John K, Kazwala R, Mfinanga GS. Knowledge of causes, clinical features and diagnosis of common zoonoses among medical practitioners in Tanzania. BMC Infect Dis 2008;8:162.

[24] Dean AS, Crump L, Greter H, et al. Clinical manifestations of human brucellosis: a systematic review and metaanalysis. PLoS Negl Trop Dis 2012;6(12):e1929.

[25] Sheahan M, O'Hagan G, Power S, et al. Brucellosis in cattle in Ireland 1998-2005: progress towards eradication continues. Ir Vet J 2006;59(4):217-21.

[26] Roushan MRH, Mohrez M, Gangi SMS, et al. Epidemiological features and clinical manifestation in 469 adult patients with brucellosis in Babol, Northern Iran. Epidemiol Infect 2004;132(6):1109-14.

[27] Ghasemi B, Mohammadia B, Majidpour MS. Epidemiology of human and animal brucellosis in Kurdistan Province in 1997-2001. Scientific Journal of Kurdistan University of Medical Sciences 2004;8(2):23-32. 